\title{
M. Heinz, Le possessif en français. Aspects sémantiques et pragmatiques
}

\section{Françoise Rigat}

\section{(2) OpenEdition}

10 Journals

\section{Édition électronique}

URL : http://journals.openedition.org/studifrancesi/33927

DOI : 10.4000/studifrancesi.33927

ISSN : 2421-5856

Éditeur

Rosenberg \& Sellier

\section{Édition imprimée}

Date de publication : 1 décembre 2005

Pagination : 695-696

ISSN : 0039-2944

\section{Référence électronique}

Françoise Rigat, « M. Heinz, Le possessif en français. Aspects sémantiques et pragmatiques », Studi

Francesi [En ligne], 147 (XLX | III) | 2005, mis en ligne le 30 novembre 2015, consulté le 18 avril 2021.

URL : http://journals.openedition.org/studifrancesi/33927 ; DOI : https://doi.org/10.4000/

studifrancesi.33927

Ce document a été généré automatiquement le 18 avril 2021.

\section{(c)}

Studi Francesi è distribuita con Licenza Creative Commons Attribuzione - Non commerciale - Non opere derivate 4.0 Internazionale. 


\title{
M. Heinz, Le possessif en français. Aspects sémantiques et pragmatiques
}

\author{
Françoise Rigat
}

\section{RÉFÉRENCE}

M. HEINZ, Le possessif en français. Aspects sémantiques et pragmatiques. Champs linguistiques, De Boeck Duculot, 2003, pp. 520.

1 L'importance de cet essai que Michaela Heinz a consacré au déterminant possessif tient aussi bien à son volume (520 pages) et à son vaste corpus rassemblant pas moins de 3400 exemples tous authentiques et référencés (tirés des romans contemporains, de la presse écrite, de la publicité, des recettes, des dictionnaires, etc.) qu'à la façon d'aborder le sujet.

2 L'auteur part de la constatation que le possessif n'exprime pas toujours la possession, loin de là. Le sens premier, le sens primaire du possessif exprime bien une relation de propriété, «avoir quelque chose», dans l'optique de celui qui «possède», ou une relation d'appartenance, dans l'optique de ce qui est "possédé», mais il exprime avant tout une relation, relation entre deux identités. Contrairement aux autres déterminants (tels que $c e, l e, u n)$, le possessif a en fait un sens qui dépasse la simple détermination du nom qu'il accompagne puisqu'il signale, de façon très économique, les fonctions grammaticales de déterminant défini et la relation de «relateur» entre le possesseur et le possédé.

3 A partir de là, l'auteur élargit ce sens relationnel du possessif. Outre la relation de possession, la relation par excellence, la seule à mériter cette dénomination (et, déplore l'auteur, la seule mise en avant dans les grammaires), le possessif indique une multitude d'autres relations telles que les relations de parenté (son oncle), de hiérarchie (ma patronne), de partie à tout (ta jambe), de résultat (son oeuvre) etc. 
4 L'ouvrage est partagé en deux parties, annoncées dans le sous-titre: la première - qui occupe les $3 / 4$ du livre - consiste en une description des propriétés sémantiques du possessif; la seconde est consacrée à ses valeurs pragmatiques.

Dans la première partie, l'auteur analyse les emplois non anaphoriques (en première mention) du possessif qui permettent de dégager le sens premier, purement lexical des syntagmes nominaux possessifs (SNposs). Déplorant l'anthropocentrisme des grammaires, elle classe les relations possessives selon les classes sémantiques ou classes d'objets du Possesseur et du Possédé, de nature animée et non. Pour l'exemple: ses locaux est analysé dans la classe Possesseur/collectivité et la classe Possédé/objet concret.

6 Nous retiendrons de cette riche partie le déséquilibre entre fait de langue et fait de discours puisque toutes les constructions du possessif ici décrites sont fréquentes et abondamment représentées en discours. Ainsi, la relation «objet concret - collectivité», quasiment absente des grammaires, est très présente dans la presse (la mairie et ses registres, Le Havre et ses chantiers); ou encore la relation «fonctionnelle», une relation plus ou moins prototypique entre deux objets indépendants entre lesquels existe une dépendance fonctionnelle (la seringue et son aiguille, le télécopieur et sa console) présente elle aussi à l'écrit, notamment dans les publicités, les notices d'utilisation etc. Parfois, cette relation se fige même dans une locution stéréotypée, une collocation typique comme par exemple une ampoule au bout de son fil, dans laquelle l'expression «au bout de son $\mathrm{N}$ » fonctionne tel un collocatif grammatical. En outre, cette étude sémantique montre que le possessif est quelques fois obligatoire, car certains objets cités sont par exemple en relation "prototypique» avec les animaux (bocal, poisson; clapier, lapin). Enfin, certains exemples ayant un caractère stylistiquement marqué, comme ceux qui illustrent la relation «le/son partie du corps», elle en conclut qu'il n'y a pas UN sens premier des syntagmes possessifs mais que leur emploi offre une large gamme de sens possibles en fonction de la situation.

7 C'est pourquoi l'auteur envisage dans la seconde partie une étude des valeurs pragmatiques $\mathrm{du}$ possessif. Un premier chapitre est consacré aux multiples connotations exprimées par le SNposs, en partant des différentes personnes grammaticales auxquelles le déterminant possessif est employé. Le possessif est ici envisagé comme un outil linguistique qui peut caresser ( $m a$ biche), blesser ( $t a$ gueule), et exprimer la condescendance (mon petit vieux), la fierté (alors mon vin?), l'injonction (mange ta soupe), l'habitude (faire son marché) etc.

8 Le deuxième chapitre traite du renforcement du possessif: il se traduit à l'écrit par une mise en relief typographique (le guillemetage par exemple), un commentaire métalinguistique qui thématise le possessif, un renforcement lexical (par l'adjectif propre, ou par l'ajout du complément prépositionnel à lui pour exprimer une valeur oppositive, du type mon bébé à moi). A l'oral, ce renforcement se présente sous forme d'une accentuation et sous forme syntaxique, par dédoublement du possesseur, par le truchement du pronom personnel disjoint (moi, ma voiture, ....).

9 Le troisième et dernier chapitre est consacré à la valeur présuppositionnelle du possessif, valeur qui fait du SNposs un mode d'expression sémantiquement dense. Pour elle, tout SNposs contient une présupposition potentielle, ce qui en fait un procédé très apprécié en publicité (grâce à ses agents actifs, Sensodyne....) ou encore dans les textes touristiques, avec la formule consacrée $X Y$ - son N1, son N2......qui suggère la notoriété (Antibes, sa plage, son cap etc...). 
10 Au total, cet ouvrage s'adresse à tous ceux qui ne retiennent de l'utilisation du possessif que les sempiternels exemples de type «M.Dupont/son livre» ou «Jean/sa soeur». Un livre stimulant, clair, très bien écrit, dont la maîtrise scientifique le dispute à l'agrément de la lecture. 